\title{
Event-Related Potential and Clinical Correlates of Neurodysfunction in Obsessive-Compulsive Disorder
}

\author{
James Towey, Gerard Bruder, Craig Tenke, Paul Leite, Concetta DeCaria, \\ David Friedman, and Eric Hollander
}

Received October 9, 1992; revised version received May 11, 1993; accepted August 9, 1993.

\begin{abstract}
The current study confirmed with increased sample sizes our preliminary findings of event-related potential (ERP) abnormalities in obsessivecompulsive disorder (OCD) (Towey et al., 1990) and examined their relationship to symptom severity, treatment response, and neurological soft signs. Unmedicated patients $(n=17)$ showed larger negativities in N200 and slow wave regions than normal control subjects $(n=16)$ to correctly detected auditory "oddball" stimuli. N200 amplitude was larger over left than right hemispheres of OCD patients, but not normal control subjects. Greater N200 amplitude correlated with less severe obsessions, better response to subsequent treatment with serotonin reuptake blockers, and fewer neurological soft signs in OCD. With increased task difficulty, N200 and P300 latencics lengthened for normal subjects, but not for OCD patients. The abnormal ERP pattern in OCD supports hypotheses of cortical hyperarousal and overfocused attention.
\end{abstract}

Key Words. Electrophysiology, anxiety disorder, cortical arousal, neurological soft signs.

The past 10-15 years has witnessed a gradual shift in focus from the psychodynamics to the psychobiology of obsessive-compulsive disorder (OCD). OCD has been viewed as a rare functional disorder that is relatively easy to diagnose, but difficult to treat (Ananth, 1985; Lelliot and Monteiro, 1986). This traditional characterization of OCD has been challenged. OCD is currently viewed as a "neurodysfunctional disorder" (Hantouche et al., 1990) and a "hidden epidemic" that afflicts about 4 million people in the United States (Jenike, 1989). Today, treatments for OCD involving "anti-obsessional medication" (e.g., The Clomipramine Study Group, 1991) and behavior therapy (e.g., Foa et al., 1985) yield substantial reductions in OCD symptoms in a majority of patients. Once called "obsessional neurosis," OCD is classified in DSM-III-R (American Psychiatric Association, 1987) as an anxiety disorder. This diagnosis, however, fails to reflect the complexities of OCD (Ross et

\footnotetext{
This research was conducted at the New York State Psychiatric Institute. James Towey, Ph.D., Gerard Bruder, Ph.D., and Craig Tenke, Ph.D., are Research Scientists in the Department of Biopsychology. Paul Leite, B.A., is an ERP technician. Concetta DeCaria, M.S., is in the OCD Biological Studies Program. David Fricdman, Ph.D., is a Rescarch Scientist in the Department of Medical Genetics. At the time this work was done, Eric Hollander, M.D., was Director of the OCD Biological Studies Program. Dr. Hollander is now Vice Chairman, Department of Psychiatry, Mt. Sinai Services, Queens Hospital Center, Jamaica, NY. (Reprint requests to Dr. J. Towey, NYSPI, 722 W. 168 Street, New York, NY 10032, USA.)
}

0165-1781/93/\$06.00@1993 Elsevier Scientific Publishers Ireland Ltd. 
al., 1987). OCD is now recognized as a "heterogeneous diagnostic syndrome" whose subtypes might be distinguished by such clinical features as treatment response and neurological soft signs (Hollander et al., 199l $c, 1992 b$ ).

The traditional view of OCD as a functional neurosis with special emphasis on its psychodynamic and psychological aspects had to be revamped to accommodate compelling evidence that pointed to an organic/biological basis for OCD (Insel et al., 1983; Lieberman, 1984; Zohar and Insel, 1987; Hollander et al., 1990, 1992b). A combination of neurophysiological, neuropsychological, and biochemical data suggested a chronic overaroused state in OCD (Turner et al., 1985). After summarizing neurological, electroencephalographic (EEG), and brain event-related potential (ERP) findings, Shagass et al. (1984a) concluded that brain function is deviant in OCD and that the deviant features appear to be relatively specific to OCD. This converging evidence does not fit any one theory of cerebral dysfunction currently proposed for OCD, but it instead provides partial support for each of three major theories: (1) increased local cortical excitability (Williamson et al., 1977), as associated with lesions in epileptic patients; (2) left frontal dysfunction (Flor-Henry et al., 1979), as associated with a loss of "inhibition" in these regions; and (3) increased arousal to minimal stimulation (Beech et al., 1983), as associated with cortical hyperactivation.

Studies using positron emission tomography (PET) have found hypermetabolism of cerebral glucose in OCD (Baxter et al., 1987; Nordahl et al., 1989). Despite methodological differences, these PET studies found evidence of hypermetabolism in the orbital frontal cortex of OCD patients. Baxter et al. (1987) point out the importance of these frontal regions in the regulation of directed attention and in the inhibition of external interfering stimuli. They suggest that the difficulty $O C D$ patients have in diverting attention from obsessions might be due to overactivity in these brain regions.

OCD patients have also shown abnormalities in studies using other brainrecording technologies, including computed tomography (e.g., Luxenberg et al., 1988), electroencephalography (e.g., Cataneo et al., 1988), and ERP (voltage changes within the brain that are time-locked to an eliciting stimulus-e.g., Beech et al., 1983; Towey et al., 1990). In contrast, studies using magnetic resonance imaging scans have generally failed to find brain structural abnormalities in OCD patients compared with control subjects (Garber et al., 1989; Kellner et al., 1991). Overall, findings based on brain recording technologies have been viewed as neither consistent nor pathognomic of OCD (Hollander et al., 1990).

In part, these inconsistencies may be due to subtle brain abnormalities in OCD that are difficult to localize. If this were the case, then sampling error in studies with small groups of subjects might easily obscure group effects and yield inconsistent findings across or within different recording techniques. One solution is to increase sample size, but this may be impractical for many brain-recording technologies. EEG/ ERP technologies are notable exceptions, however, because they are relatively inexpensive and noninvasive. Moreover, ERPs can provide unique information about psychophysiological correlates of varying cognitive task demands. The excellent temporal resolution provided by ERPs can complement spatial informa- 
tion derived from other recording techniques like PET. Reports of ERP abnormalities in OCD have been relatively consistent. For example, studies in somatosensory (Shagass et al., 1984a, 1984b, 1988), visual (Ciesielski et al., 1981; Beech et al., 1983), and auditory modalities (Towey et al., 1990) have found evidence of distinctive ERP features in OCD, which are consistent with increased cortical arousal. In contrast to normal control subjects or other psychiatric groups, OCD patients in these studies had ERP waveforms that were distinguished by enhanced negativities, reduced latencies, or both.

This is the final report of a study for which preliminary ERP data were presented for 10 OCD patients and 10 normal control subjects (Towey et al., 1990). The current study presents data for increased sample sizes of 17 patients and 16 normal control subjects that confirm our initial findings: (1) enhanced negativities in OCD patients extending from the N200 component to late slow wave activity, and (2) N200 and P300 latency increased with greater task difficulty for normal control subjects but not for OCD patients. Larger sample sizes were necessary to examine relationships between ERP abnormalities and clinical features in OCD (e.g., symptom severity, subsequent treatment response, and neurological soft signs). Larger samples were also needed to provide sufficient statistical power to evaluate a trend, noted in the preliminary study, for $\mathrm{N} 200$ amplitude to be maximal in OCD at sites overlying the left hemisphere. This ERP asymmetry in OCD would be noteworthy in light of PET findings of overaroused left frontal regions in OCD patients (Baxter et al., 1987).

\section{Methods}

Subjects. Subjects were screened for the following characteristics: normal hearing, righthandedness, age (18-55 years), and absence of major medical problems. Patients were drug free for at least 2 weeks before ERP testing, met $D S M-I I I-R$ criteria for OCD, had no focal lesion on neurological examination, and scored below 16 on the Hamilton Rating Scale for Depression (Hamilton, 1960). The OCD diagnosis was confirmed independently by a trained clinician using a modified Schedule for Affective Disorders and Schizophrenia-Lifetime version (Mannuzza et al., 1986). Normal subjects did not currently meet criteria for any major psychiatric disorder. Each subject was instructed not to discuss anything that might reveal his or her diagnostic status to the ERP staff. See Towey et al. (1990) for further details.

There were 17 OCD patients (13 men, 4 women; mean age 35.94; SD 7.29) and 16 normal control subjects (5 men, 11 women; mean age 31.63 ; SD 7.68). Gender was significantly different between groups $\left(x^{2}=5.10, p<0.02\right)$, but age was not. In the preliminary report (Towey et al., 1990), samples of 10 patients and 10 control subjects did not differ in gender. The lack of a gender match in the final samples was a consequence of maintaining the study blind, and the fact that patients and control subjects were referred for ERP testing without regard to gender. However, gender effects did not influence any key ERP findings of the current study, and ERP findings for the final samples were essentially the same as those for the preliminary samples where there was no group difference in gender.

ERP Task. Subjects were told to depress a response button whenever they heard the rarer and louder of two clicks, without any additional instructions about speed or accuracy. The probability of the louder clicks (targets) was 0.25 and that of the softer clicks (nontargets) was 0.75 . The intensity difference between target and nontarget clicks was either $12 \mathrm{~dB}$ (easy condition) or $8 \mathrm{~dB}$ (difficult condition) in a four-block session (easy-difficult-difficult-easy). Each block consisted of 105 clicks with an interstimulus interval of 1.6 seconds. The first five clicks were always nontargets to provide a reference. The click stimuli were generated by a 
negative-going electrical pulse with an instantaneous onset and an exponential return to base. The duration of the exponential return to base was approximately $1 \mathrm{msec}$. Click stimuli were presented binaurally by a matched pair of Sennheisser HD224X earphones, while subjects sat in a sound-attenuated room facing a light-emitting diode that served as a fixation light to reduce eye movements.

ERP Recording and Analysis. Scalp electrodes were used to record from midline ( $\mathrm{Fz}-\mathrm{Cz}-$ $\mathrm{Pz}_{\mathrm{Z}} \mathrm{Oz}$ ), right hemisphere (F4-C4-P4-O2), and left hemisphere sites (F3-C3-P3-O1), with nosetip for reference and left mastoid for ground. Vertical electro-oculographic (EOG) artifact was monitored from a bipolar pair of electrodes located at supraorbital and infraorbital sites of the right eye; horizontal EOG was monitored from a bipolar pair of electrodes located at the outer canthi of both eyes. Amplifier gains were set at 10,000 for EEG channels and 5,000 for EOG channels. EOG data were appropriately rescaled before storage. The band pass was 0.032-50 Hz. A minicomputer acquired the ERP data at $10-\mathrm{msec}$ intervals for $200 \mathrm{msec}$ prestimulus and $1000 \mathrm{msec}$ poststimulus. ERP trials that exceeded $50 \mu \mathrm{V}$ root mean square amplitude were eliminated, and the remaining ERP trials were corrected for eye movements with a linear regression technique (Verleger et al., 1982; Gratton et al., 1983). ERP waveforms were then filtered to an equivalent upper cutoff frequency $(-3 \mathrm{~dB})$ of $4.9 \mathrm{~Hz}$ (Ruchkin and Glaser, 1978). On the average, the number of target trials remaining after artifact removal differed for conditions (easy condition $=35$ trials; difficult condition $=24$ trials) but not groups $(\mathrm{OCD}=28$ trials; normal subjects $=32$ trials). Significantly fewer trials remained for the difficult condition than for the easy condition (condition: $F=51.31 ; d f=1,31 ; p<0.001$ ), but there was no condition $\times$ group interaction.

Analysis of variance (ANOVA) was used to confirm apparent differences for each ERP component of interest. Baseline-to-peak amplitude was measured as the minimum/maximum within the regions of 50-150 msec for N100, $155-250 \mathrm{msec}$ for N200, and 275-550 mscc for P300. Slow wave was measured as the average amplitude within the $600-1000 \mathrm{msec}$ region. ANOVAs for midline ERP data used the between-group factor of group (OCD, control) and within-group factors of stimulus (target, nontarget), task condition (difficult, easy), and electrode location ( $\mathrm{Fz}, \mathrm{Pz}, \mathrm{Cz}$, and $\mathrm{Oz}$ ). Greenhouse-Geisser adjusted degrees of freedom $(d f)$ were used when appropriate, i.e., to adjust for repeated measurements, using BMDP4V. ANOVAs for lateral ERP data used these same factors plus one for hemisphere (left, right).

Neurological Soft Signs. Neurological soft signs are nonlocalizing deviant performances on a motor or sensory test where no other sign of a focal neurological disorder is present. Abnormalities may include disorders of coordination, involuntary movements, and sensory signs. Previous studies have documented a link between neurological soft signs and several psychiatric disorders. In a prospective study, for example, patients with soft signs detected at age 7 and symptoms of anxious withdrawal in adolescence were found to develop OCD, other anxiety disorders, and affective disorders in adulthood (Hollander et al., 1991a). The soft sign examination involved four categories (fine motor coordination, involuntary movements, sensory function, and visuospatial tasks) and a total of 20 individual tasks. This examination was administered and then rated by a trained psychiatrist or neurologist without knowledge of the subject's diagnosis. Interrater reliability was established for a subgroup of eight subjects to range from 0.58 to 0.95 for all test items. Further details are presented elsewhere (Hollander et al., 1991a).

Clinical Ratings. Clinical ratings were performed during a drug-free baseline period (when ERP and soft signs were mcasurcd) and again after treatment with anti-obscssional medication. Six OCD patients were treated with fluoxetine (final dose level ranged between 40-80 $\mathrm{mg}$ ), six were treated with clomipramine (final dose level between 250 and $300 \mathrm{mg}$ ), and the remaining five patients did not complete a drug treatment phase. Severity of OCD symptoms at baseline and following treatment was assessed with the Yale-Brown Obsessive-Compulsive Scale (Y-BOCS; Goodman et al., 1989a, 1989b). See Hollander et al. (1991b) for further details. 


\section{Results}

Behavioral Data. Increasing task difficulty resulted in the expected decrease in accuracy levels for both OCD patients and normal control subjects. There was a significant decrease in correct detections of targets $(F=19.59, p<0.01)$ and a corresponding increase in false alarms $(F=7.82, p<0.009)$, but there was no significant difference in accuracy between groups. The mean percentage of correct detections for the easy and difficult conditions was $85 \%$ and $73 \%$ for OCD patients, and $90 \%$ and $75 \%$ for normal control subjects.

Average ERP Waveforms. Fig. 1 shows group mean waveforms to target stimuli recorded during the easy and difficult conditions (correct trials only) at the four midline sites (Fz-Cz-Pz-Oz) and corresponding lateral sites. Waveforms to nontarget stimuli are not shown because they were of small amplitude and revealed little or no difference between groups. The waveforms to targets in Fig. 1 show a prominent N200 component with a frontocentral maximum and a P300 component with a parietal maximum. This is followed by an extended period of slow wave activity.

Fig. 1. Grand mean event-related potential waveforms for obsessivecompulsive disorder (OCD) and normal groups generated during easy and difficult conditions to correctly detected target stimuli

Easy

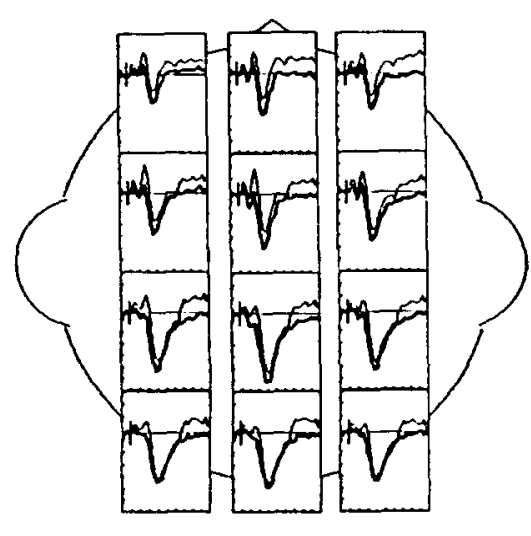

Difficult

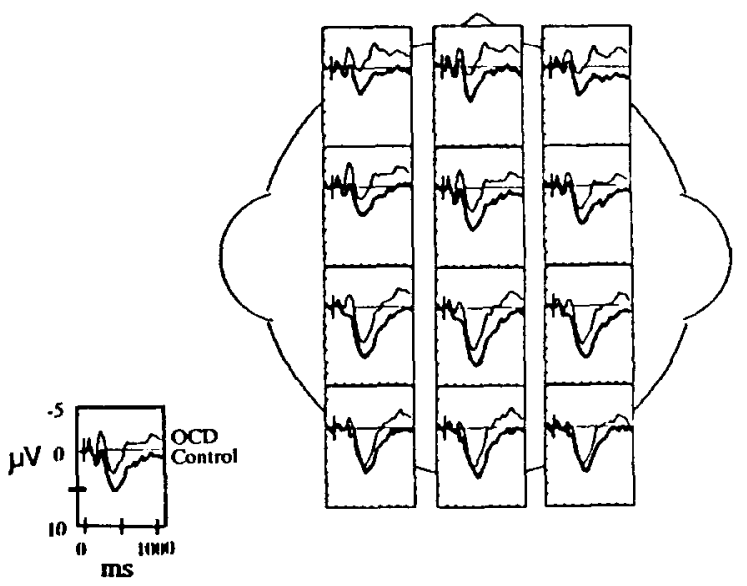

The event-related potential waveforms are shown as recordings from left (F3-C3-P3-O1), midline (Fz-Cz-Pz-Oz), and right (F4-C4-P4-O2) scalp sites.

There were clear differences in these target waveforms between groups, with greater negativity in OCD patients beginning in the region of N200 and extending beyond P300 into the region of negative slow wave activity. The differences between groups in N200 and slow wave amplitudes can also be seen in Table 1, which lists ERP amplitudes to target stimuli according to electrode (midline and lateral scalp sites), group (OCD, normal) and condition (easy, difficult). Notice in Table 1 that N200 
and slow wave components are consistently more negative for OCD than normal groups at each site, regardless of condition. Groups also appeared to differ concerning N100 and P300 amplitudes (Fig. 1), but these trends were not statistically significant for midline or lateral sites, as described below.

Table 1. Mean amplitudes of N200 and slow wave (SW) components to target stimuli as recorded from midline and parasagittal scalp sites for obsessive-compulsive disorder (OCD) and normal groups

\begin{tabular}{|c|c|c|c|c|c|}
\hline & & \multicolumn{2}{|c|}{ N200 amplitudes } & \multicolumn{2}{|c|}{ SW amplitudes } \\
\hline & & Easy & Difficult & Easy & Difficult \\
\hline \multicolumn{6}{|l|}{ OCD patients } \\
\hline \multirow[t]{5}{*}{ Left } & F3 & -3.43 & -2.98 & -1.51 & -1.93 \\
\hline & C3 & -4.22 & -3.55 & -1.39 & -1.88 \\
\hline & P3 & -2.89 & -2.09 & -1.10 & -1.23 \\
\hline & 01 & -2.04 & -1.54 & -0.98 & -1.14 \\
\hline & $\mathrm{FZ}$ & -3.18 & -2.93 & -1.68 & -2.22 \\
\hline \multirow[t]{3}{*}{ Midline } & $\mathrm{CZ}$ & -3.79 & -2.78 & -1.17 & -1.20 \\
\hline & $\mathrm{PZ}$ & -1.69 & -1.40 & -0.53 & -0.99 \\
\hline & $O Z$ & -1.57 & -1.14 & -1.15 & -1.37 \\
\hline \multirow[t]{4}{*}{ Right } & $\mathrm{F} 4$ & -3.03 & -2.73 & -1.77 & -1.64 \\
\hline & $\mathrm{C} 4$ & -3.06 & -2.44 & -0.72 & -0.70 \\
\hline & $\mathrm{P} 4$ & -1.93 & -1.46 & -0.44 & -0.57 \\
\hline & $\mathrm{O} 2$ & -1.64 & -0.98 & -0.67 & -0.62 \\
\hline Grand mean & & $-2.71(2.60)^{1}$ & $-2.17(2.81)$ & $-1.09(2.23)$ & $-1.29(2.82)$ \\
\hline \multicolumn{6}{|c|}{ Normal control subjects } \\
\hline \multirow[t]{4}{*}{ Left } & F3 & -1.38 & -0.84 & -0.51 & 0.39 \\
\hline & $\mathrm{C} 3$ & -1.43 & -1.13 & -0.14 & 0.43 \\
\hline & P3 & -0.16 & -0.29 & 0.90 & 1.29 \\
\hline & 01 & -0.23 & -0.93 & 0.67 & 0.75 \\
\hline \multirow[t]{4}{*}{ Midline } & $\mathrm{FZ}$ & -1.42 & -1.37 & 0.13 & 0.41 \\
\hline & $C Z$ & -0.77 & -0.70 & 0.38 & 1.08 \\
\hline & $P Z$ & 0.63 & 0.33 & 1.29 & 1.63 \\
\hline & $O Z$ & 0.10 & -0.54 & 0.69 & 0.84 \\
\hline \multirow[t]{4}{*}{ Right } & $\mathrm{F} 4$ & -1.21 & -1.02 & 0.28 & 0.84 \\
\hline & $\mathrm{C} 4$ & -1.23 & -1.11 & 0.92 & 0.93 \\
\hline & $\mathrm{P} 4$ & -0.04 & -0.19 & 0.99 & 1.44 \\
\hline & $\mathrm{O} 2$ & -0.18 & -0.88 & 0.58 & 0.75 \\
\hline Grand mean & & $-0.61(1.45)$ & $-0.72(1.92)$ & $0.52(3.28)$ & $0.99(2.26)$ \\
\hline
\end{tabular}

1. Standard deviation.

Midline ERP Data. Some differences in ER Ps that were visible in Fig. 1 at midline sites were confirmed by an ANOVA of ERP amplitudes to target and nontarget stimuli. Regardless of task difficulty level, OCD patients showed larger negative amplitudes than normal control subjects for N200 (Group: $F=9.30 ; d f=1,31$; $p<0.01$ ) and negative slow wave activity (group: $F=6.09 ; d f=1,31 ; p<0.025$ ). For N100 and P300 amplitude, however, there was no main effect of group and no interaction involving group. Regardless of group, baseline-to-peak amplitudes were 
larger for targets than for nontargets for $\mathrm{N} 200$ at anterior sites (stimulus $\times$ electrode: $F=15.65 ; d f=2,67 ; p<0.001$ ) and for $\mathrm{P} 300$ at posterior sites (stimulus $X$ electrode: $F=24.79 ; d f=2,55 ; p<0.001$ ).

Table 2 shows group mean N200 and P300 latencies elicited by correctly detected targets during the easy and difficult conditions at the four midline sites. Normal control subjects showed the expected increase in N200 and P300 latency with increasing task difficulty, whereas OCD patients did not. An ANOVA of the latency data confirmed these impressions (group $\times$ condition interaction for N200 latency: $F=4.31 ; d f=1,31 ; p<0.05$; for P300 latency: $F=6.30 ; d f=1,31 ; p<0.025$ ). Analysis of simple effects showed that increasing task difficulty level resulted in an increase in N200 latency $(F=8.14 ; d f=1,31 ; p<0.01)$ and P300 latency $(F=13.77 ; d f=1,31 ; p<0.01)$ for normal control subjects, but not OCD patients. The trend for OCD patients to have shorter P300 latency than normal control subjects for the difficult condition, which was statistically significant in our preliminary report (Towey et al., 1990), was not significant in these larger samples.

Table 2. Mean latencies of $\mathrm{N200}$ and P300 components to target stimuli as recorded from midline scalp sites for obsessive-compulsive disorder (OCD) and normal groups

\begin{tabular}{llllllc}
\hline & & \multicolumn{2}{c}{ N200 latencies } & & \multicolumn{2}{c}{ P300 latencies } \\
& & Easy & Difficult & & Easy & Difficult \\
\hline OCD patients & FZ & 243 & 248 & & 381 & 386 \\
& CZ & 238 & 242 & & 386 & 398 \\
& $\mathrm{PZ}$ & 234 & 232 & & 408 & 402 \\
& $\mathrm{OZ}$ & 231 & 222 & & 411 & 403 \\
Grand mean & & $236(21.3)^{1}$ & $236(22.3)$ & & $397(54.4)$ & $397(72.9)$ \\
Normal control subjects & $\mathrm{FZ}$ & 227 & 247 & & 387 & 452 \\
& $\mathrm{CZ}$ & 227 & 242 & & 391 & 456 \\
& $\mathrm{PZ}$ & 222 & 237 & & 395 & 456 \\
Grand mean & $\mathrm{OZ}$ & 224 & 232 & & 397 & 452 \\
& & $225(14.5)$ & $240(34.8)$ & $393(47.0)$ & $454(62.4)$ \\
\hline
\end{tabular}

1. Standard deviation.

Lateral ERP Data. ANOVAs of lateral ERP data confirmed that ERP findings for midline electrodes were also evident for the electrode sites over left and right hemispheres. For example, the same interactions of group $\times$ task difficulty were evident for latency of $\mathrm{N} 200(F=5.55 ; d f=1,31 ; p<0.05)$ and P300 $(F=5.51$; $d f=1,31 ; p<0.05$ ). Here also, OCD patients showed larger negativities than normal control subjects for $\mathrm{N} 200(F=8.80 ; d f=1,31 ; p<0.01)$ and slow wave $(F=7.66 ; d f=1,31 ; p<0.01)$. Similarly, there was no group difference in $\mathrm{N} 100$ or P300 amplitude.

Table 1 shows that OCD patients also produced larger negativities to targets over left than right hemispheres. The ANOVAs of ERPs at lateral sites revealed hemispheric asymmetries involving negativities in N200 and slow wave regions to target stimuli but not nontarget stimuli (hemisphere $X$ stimulus interaction: N200 amplitude: $F=11.82 ; d f=1,31 ; p<0.01$; slow wave amplitude: $F=8.10 ; d f=1$, 
$31 ; p<0.01)$. For target stimuli, there was generally greater negativity over the left hemisphere than the right hemisphere for both $\mathrm{N} 200(F=10.06 ; d f=1,31 ; p<0.01)$ and slow wave activity $(F=5.22 ; d f=1,31 ; p<0.05)$. Because these hemispheric asymmetries occurred only to target stimuli, difference waveforms were generated by subtracting waveforms for nontarget stimuli from those for target stimuli (Fig. 2). Difference waveforms show that hemispheric asymmetries were more pronounced in OCD patients than in normal control subjects. The ANOVA revealed that the hemispheric asymmetry of $\mathrm{N} 200$ was dependent on group and stimulus type (group $\times$ hemisphere $\times$ stimulus interaction: $F=9.09 ; d f=1,31 ; p<0.01$ ). This, however, was not the case for slow wave activity. As can be seen in Fig. 2, the amplitude of N200 to target relative to nontarget stimuli was larger over the left hemisphere than the right hemisphere of $O C D$ patients (hemisphere $X$ stimulus interaction: $F=21.47 ; d f=1,31 ; p<0.01$ ), whereas normal control subjects did not show this $\mathrm{N} 200$ asymmetry. It should also be noted that this group difference in N200

Fig. 2. Grand mean event-related potential difference waveforms (target minus nontarget stimuli) for scalp electrodes over left and right hemispheres in obsessive-compulsive disorder (OCD) and normal control groups

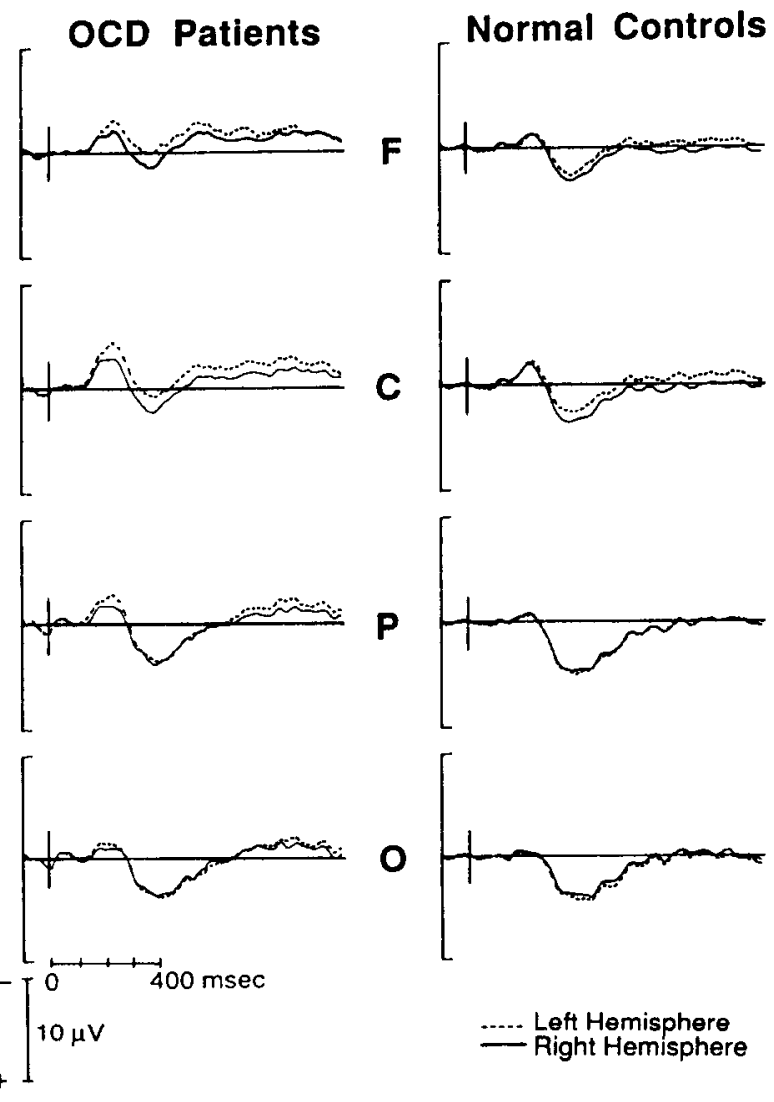


amplitude was statistically significant when only the new samples of seven OCD patients and six normal control subjects were analyzed (group $X$ hemisphere $X$ stimulus interaction: $F=7.13 ; d f=1,11 ; p<0.02$ ). This was only a trend (group $\times$ hemisphere $X$ stimulus interaction for $\mathrm{N} 200$ amplitude: $F=3.60 ; d f=1,18$; $p=0.07)$ for the preliminary samples of $10 \mathrm{OCD}$ patients and 10 normal control subjects (Towey et al., 1990).

Correlational Analyses. The enhanced negativities in OCD for N200 were significantly correlated with clinical features of OCD. Parametric and nonparametric tests produced the same results. In these analyses, N200 amplitudes of OCD patients were averaged across frontal and central electrode sites, where N200 was maximal, and across hemispheres. Fig. 3 shows scatterplots relating N200 amplitude (negative amplitudes up) to three clinical features. N200 amplitudes of OCD patients were inversely related to their pretreatment obsession scores on the Y-BOCS (Pearson $r=0.78, p<0.01$; Spearman $\rho=0.76, p<0.01$ ). Patients with larger N200 amplitudes had less severe obsessions before treatment. N200 amplitudes of OCD patients also correlated with pretreatment to posttreatment change in their total scores on the Y-BOCS (Pearson $r=-0.61, p<0.05$; Spearman $\rho$ $=-0.45, p<0.10$ ). Patients with larger $\mathrm{N} 200$ amplitudes showed the greatest improvement in obsessive-compulsive symptoms following treatment (Y-BOCS change $=$ pretreatment - posttreatment scores). Patients with larger N200 amplitudes also tended to have fewer neurological soft signs (Pearson $r=0.54$, $p<0.05$; Spearman $\rho=0.63, p<0.05$ ). Unlike $\mathrm{N} 200$, negative slow wave amplitude did not correlate significantly with clinical features or neurological soft signs. Fig. 3. Scattergrams relating N200 amplitude (negative amplitude up) and
clinical features in obsessive-compulsive disorder
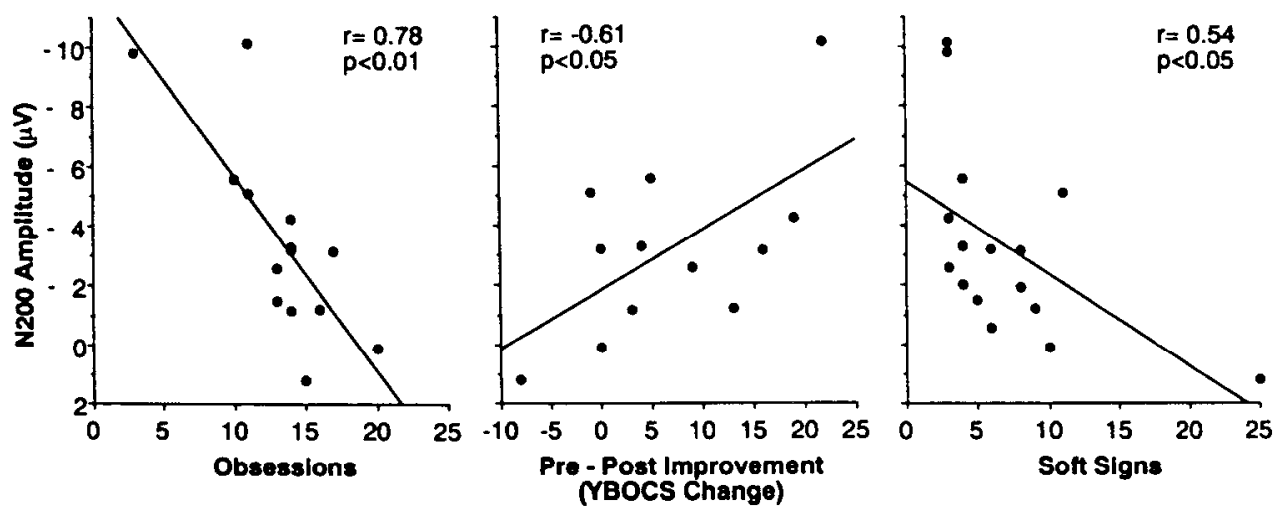

Y-BOCS $=$ Yale-Brown Obsessive-Compulsive Scale. 


\section{Discussion}

The strongest and perhaps most compelling findings of this study were the enhanced negative potentials in OCD. This confirms in larger samples what was observed in our preliminary report (Towey et al., 1990). Compared with normal control subjects, OCD patients had a larger negativity beginning at the N200 component and extending into the slow wave region. Enhanced negative potentials in OCD have similarly been reported for the N60 somatosensory evoked response (Shagass et al., $1984 a, 1984 b$ ) and for the late component of contingent negative variation (CNV), the so-called "expectancy wave" or E-wave (Sartory and Master, 1984). Our interpretation is that overaroused and overfocused attention in OCD patients results in enlarged negative potentials to salient stimuli. Selective attention to auditory stimuli is known to be reflected in "processing negativity," which has both early (100-300 $\mathrm{msec})$ and late $(300-500 \mathrm{msec})$ phases (Naatanen, 1982). Processing negativity is thought to be related to the frontal mechanism controlling directed attention (Naatanen and Picton, 1987; Naatanen, 1990). The enhanced negativities in OCD could, therefore, stem directly from hyperactivation of this frontal cortical mechanism, which would also be consistent with evidence of hypermetabolism in the orbital frontal cortex of OCD patients (Baxter et al., 1987; Insel, 1992).

It should, however, be noted that other ERP components, such as mismatch negativity (N2a), classic N200 (N2b), early CNV (O-wave), or late CNV (E-wave) could have contributed to some degree to the enhanced and extended negativity in OCD. In this regard, Miller (1986) has found that normal volunteers identified by questionnaire to be at risk for mental illness (e.g., anhedonic subjects) had increased amplitudes of $\mathrm{N} 200$ and negative slow wave activity when compared with control subjects. A study is now underway to define further the ERP components contributing to the enhanced and extended negativities in OCD. Preliminary ERP findings for a selective listening task support our "processing negativity interpretation," in that attention-related processing negativity was enhanced and extended in OCD patients.

Normal subjects in this study and in earlier studies (Ritter et al., 1979; Towey et al., 1980) showed an increase in N200 and P300 latency with increased difficulty in discriminating target from nontarget auditory stimuli. The findings for OCD patients in this study, as well as for obsessional neurotics in prior studies using visual-spatial discrimination tasks (Ciesielski et al., 1981; Beech et al., 1983), failed to show this increase in N200 or P300 latency with increasing task difficulty. One interpretation is that overaroused and overfocused attention to test stimuli in OCD patients might act to facilitate information processing, particularly under conditions involving heightened cognitive demands. Indeed, there was a nonsignificant trend for OCD patients to have shorter P300 latencies than normal control subjects for the more difficult discrimination condition, a finding that was statistically significant in prior reports (Ciesielski et al., 1981; Beech et al., 1983; Towey et al., 1990). Finding reduced P300 latencies in OCD is noteworthy because other psychiatric groups, such as schizophrenic or depressive patients, typically show either no difference or longer latencies than normal control subjects (Levitt et al., 1973; Josiassen et al., 1986; Roth et al., 1986; Bruder et al., 1991). 
We have confirmed our preliminary finding of a hemispheric asymmetry of N200 amplitude to target stimuli in OCD patients and not in normal control subjects. The enhanced N200 amplitude in OCD patients was more marked over the left than the right hemisphere. One should be cautious about interpreting this abnormal N200 asymmetry in OCD because scalp-recorded ERPs do not necessarily reflect activity from directly underlying regions of the brain. This asymmetry is consistent, however, with other ERP evidence of left hemisphere hyperresponsiveness in OCD (Shagass et al., 1984a, 1984b), with increased metabolic rate in the left orbital gyrus of OCD patients (Baxter et al., 1987), and with cerebral blood flow during "imaginal flooding" being maximal in the left temporal lobe of OCD patients (Zohar et al., 1989).

Other studies have found left hemisphere dysfunction in OCD as evidenced by neuropsychological test performance (Flor-Henry et al., 1979) or by the absence of the normal right ear (left hemisphere) advantage for dichotic consonant-vowel syllables (Rapoport et al., 1981). The latter finding was replicated by Wexler and Goodman (1991) using dichotic fused word and syllable tests; they suggested that the asymmetric electrical and metabolic abnormalities in OCD may be associated with a decrease in left hemisphere function. A possible mechanism accounting for the presence of both left hemisphere hyperactivity and dysfunction in OCD is suggested by the ERP findings for epileptic patients following unilateral removal of the anterior temporal lobe (Johnson, 1988). Similar to our OCD patients, Johnson's patients with left temporal lobectomies had abnormally enhanced negativities extending from N100 into the slow wave region of the ERP waveform. Left-sided dysfunction of a system involving reciprocal inhibition of limbic and frontal regions (Gray, 1982) could result in a release from inhibition and an increase in negative ERPs generated or modulated in these regions (Naatanen and Picton, 1987). Alternatively, heightened left-sided activation of this system in OCD, or other anxiety disorders, could in itself act to inhibit or interfere with left hemisphere processing capacity (Tucker, 1981; Tucker and Williamson, 1984). Further study, however, is needed to determine if evidence of left hemisphere hyperactivation (e.g., asymmetric ERP negativities) and left hemisphere dysfunction (reduced ear advantages on verbal dichotic tasks) occur in the same OCD patients, and to evaluate whether these abnormalities are specific to OCD or occur in other anxiety disorders as well. We have, for instance, found left hemisphere activation in depersonalization disorder, a disorder closely related to OCD (Hollander et al., 1992a).

Finally, the larger samples in this study provided an opportunity to examine the relationship between abnormal ERPs in OCD patients and their clinical or neurological features. OCD patients with larger N200 amplitudes had less severe obsessions, better response to subsequent treatment with serotonin reuptake blockers, and fewer neurological soft signs. Such correlations support the view that OCD is a heterogeneous diagnostic syndrome (Hollander et al., 1991c, 1992b) and exists along a continuum with different clinical and neurological features. Some researchers have speculated, for example, that OCD may belong between Tourette's syndrome and attentional deficit disorder (Drake et al., 1992). The present findings are consistent with the views that OCD patients who exhibit less neurological impairment show more evidence of cortical hyperarousal, which is manifest 
electrophysiologically as enhanced ERP negativities and clinically as mild to moderate obsessions. This OCD subgroup responds well to subsequent treatment with serotonin reuptake blockers. At the other extreme, OCD patients with greater nonspecific neurological impairment are characterized by less ERP negativity, greater severity of obsessions, and poor treatment response. Such relationships suggest the potential value of ERP measures for identifying a subtype of treatmentresponsive OCD patients with distinctive clinical and psychobiological features.

Because OCD remains such an "intriguing mystery" (Insel, 1992), it seems both necessary and worthwhile to go beyond $D S M-I I I-R$ criteria and, whenever possible, to link OCD phenomenology with measures of brain function. In this effort, further study of "endogenous" ERP abnormalities in OCD could also help clarify the exact nature of the cognitive disorder in OCD. Just as scientific analyses of aphasic patients helped to clarify the processing of linguistic cues, scientific studies of OCD patients may ultimately elucidate the processing of internally generated schemes related to obsessions and compulsions (Insel, 1992). Such insights should help us not only to understand $\mathrm{OCD}$ better, but to improve our understanding of other psychiatric disorders that exhibit obsessive-compulsive symptoms as well.

Acknowledgments. The research reported was supported in part by a grant to Dr. Towey from the National Institute of Mental Health (MH-44815) and RSDA awards to Dr. Hollander (MH-00750) and Dr. Friedman (MH-00510). A Faculty Development Award to Dr. Towey from Mercy College also provided some support.

\section{References}

American Psychiatric Association. DSM-III-R: Diagnostic and Statistical Manual of Mental Disorders. 3rd ed., revised. Washington, DC: American Psychiatric Press, 1987.

Ananth, J. Pharmacology of obsessive-compulsive disorders. In: Mavissakalian, M.; Turner, S.M.; and Michelson, L., eds. Obsessive-Compulsive Disorder: Psychological and Pharmacological Treatment. New York: Plenum Press, 1985.

Baxter, L.E., Jr.; Phelps, M.E.; Mazziotta, J.C.; Guze, B.H.; Schwartz, J.M.; and Selin, C.E. Local cerebral glucose metabolic rates in obsessive-compulsive disorder: A comparison with rates in unipolar depression and in normal controls. Archives of General Psychiatry, 44:211-218, 1987.

Beech, H.R.; Ciesielski, K.T.; and Gordon, P.K. Further observations of evoked potential in obsessional patients. British Journal of Psychiatry, 142:605-609, 1983.

Bruder, G.E.; Towey, J.P.; Stewart, J.W.; Friedman, D.; Tenke, C.; and Quitkin, F.M. Event-related potentials in depression: Influence of task, stimulus field and clinical features on P3 latency. Biological Psychiatry, 30:233-246, 1991.

Cataneo, A.M.; Biserni, P.; Cazzullo, C.L.; Locatelli, M.; Gambini, O.; and Scarone, S. Neurofunctional assessment of obsessive-compulsive disorder: A neurophysiological study.

Research Communications in Psychology, Psychiatry and Behavior, 13:113-122, 1988.

Ciesielski, K.T.; Beech, H.R.; and Gordon, P.K. Some electrophysiological observations in obsessional states. British Journal of Psychiatry, 138:479-484, 1981.

The Clomipramine Collaborative Study Group. Clomipramine in the treatment of patients with obsessive-compulsive disorder. Archives of General Psychiatry, 48:730-738, 1991.

Drake, M.E., Jr.; Hietter, S.A.; Padamadan, H.; Bogner, J.E.; Andrews, J.M.; and Weate, S. Auditory evoked potentials in Gilles de la Tourette syndrome. Clinical Electroencephalography, 23:19-23, 1992. 
Flor-Henry, P.; Yeudall, L.T.; Koles, Z.J.; and Howarth, B.G. Neuropsychological and power spectral EEG investigations of the obsessive-compulsive syndrome. Biological Psychiatry, 14:119-129, 1979.

Foa, E.B.; Steketee, G.S.; and Ozarow, B.J. Behavior therapy with obsessive-compulsives: From theory to treatment. In: Mavissakalian, M.; Turner, S.M.; and Michelson, L., eds. Obsessive-Compulsive Disorder: Psychological and Pharmacological Treatment. New York: Plenum Press, 1985.

Garber, H.J.; Ananth, J.V.; Chiu, L.C.; and Griswold, V.J. Nuclear magnetic resonance study of obsessive-compulsive disorder. American Journal of Psychiatry, 146:1001-1005, 1989.

Goodman, W.K.; Price, L.H.; Rasmussen, S.A.; Mazure, C.; Fleischmann, R.; Hill, C.; Heninger, G.R.; and Charney, D.S. The Yale-Brown Obsessive Compulsive Scale (Y-BOCS): I. Development, use and reliability. Archives of General Psychiatry, 46:1006-1011, 1989a.

Goodman, W.K.; Price, L.H.; Rasmussen, S.A.; Mazure, C.; Delgado, P.; Heninger, G.R.; and Charney, D.S. The Yale-Brown Obsessive-Compulsive Scale (Y-BOCS): II. Validity. Archives of General Psychiatry, 46:1012-1016, $1989 \mathrm{~h}$.

Gratton, G.; Coles, M.G.H.; and Donchin, E. A new method for off-line removal of ocular artifact. Electroencephalography and Clinical Neurophysiology, 55:468-484, 1983.

Gray, J. The Neuropsychology of Anxiety. New York: Oxford University Press, 1982.

Hamilton, M. A rating scale for depression. Journal of Neurology, Neurosurgery, and Psychiatry, 23:56-62, 1960 .

Hantouche, E.; Gueguen, B.; Martinot, J.L.; and Gasnault, J. Arguments for cerebral dysfunction in obsessive-compulsive disorder: A review and synthesis of the literature. Encephale, 16:23-30, 1990.

Hollander, E.; Carrasco, J.L.; Mullen, L.S.; Trungold, S.; DeCaria, C.; and Towey, J. Left hemispheric activation in depersonalization disorder: A case report. Biological Psychiatry, 31:1157-1162, 1992a.

Hollander, E.; DeCaria, C.; Aronowitz, B.; Klein, D.F.; Liebowitz, M.R.; and Shaffer, D. A pilot follow-up study of childhood soft signs and the development of adult psychopathology. Journal of Neuropsychiatry, 3:186-189, 1991a.

Hollander, E.; DeCaria, C.; Gully, R.; Nitescu, A.; Suckow, R.F.; Gorman, J.M.; Klein, D.F.; and Liebowitz, M.R. Effects of chronic fluoxetine treatment on behavioral and neuroendocrine responses to meta-chlorophenylpiperazine in obsessive-compulsive disorder. Psychiatry Research, 36:1-17, 1991b.

Hollander, E.; DeCaria, C.; Nitescu, A.; Gully, R.; Suckow, R.F.; Cooper, T.A.; Gorman, J.M.; Klein, D.F.; and Liebowitz, M.R. Serotonergic function in obsessive-compulsive disorder: Behavioral and neuroendocrine responses to oral $m$-clorophenylpiperazine and fenfluramine in patients and healthy volunteers. Archives of General Psychiatry, 49:21-28, $1992 b$.

Hollander, E.; DeCaria, C.M.; Saoud, J.B.; Klein, D.F.; and Liebowitz, M.R. Neurologic soft signs in obsessive-compulsive disorder. (Letter) Archives of General Psychiatry, 48:278$279,1991 c$.

Hollander, E.; Schiffman, E.; Cohen, B.; Rivera-Stein, M.A.; Rosen, W.; Gorman, J.M.; Fyer, A.; Papp, L.; and Liebowitz, M.R. Signs of central nervous system dysfunction in obsessive-compulsive disorder. Archives of General Psychiatry, 47:27-32, 1990.

Insel, T.R. Toward a neuroanatomy of obsessive-compulsive disorder. Archives of General Psychiatry, 49:739-744, 1992.

Insel, T.R.; Donnelly, E.F.; Lalakea, M.L.; Alterman, I.S.; and Murphy, D.L. Neurological and neuropsychological studies of patients with obsessive-compulsive disorder. Biological Psychiatry, 18:741-751, 1983.

Jenike, M.A. Editorial. Obsessive-compulsive and related disorders: A hidden epidemic. New England Journal of Medicine, 321:539-541, 1989.

Johnson, R., Jr. Scalp-recorded P300 activity in patients following unilateral temporal lobectomy. Brain, 111:1517-1529, 1988. 
Josiassen, R.C.; Roemer, R.A.; Shagass, C.; and Straumanis, J.J. Attention-related effects on somatosensory-evoked potentials in nonpsychotic dysphoric psychiatric patients. In: Shagass, C.; Josiassen, R.C.; and Roemer, R.A., eds. Brain Electrical Potentials and Psychopathology. Amsterdam: Elsevier Science Publishers, 1986.

Kellner, C.H.; Jolley, R.R.; Holgate, R.C.; Austin, L.; Lydiard, R.B.; Laraia, M.; and Ballenger, J.C. Brain MRI in obsessive-compulsive disorder. Psychiatry Research, 36:45-49, 1991.

Lelliott, P.T., and Monteiro, W.O. Drug treatment of obsessive-compulsive disorder. Drugs, 31:75-80, 1986.

Levitt, R.A.; Sutton, S.; and Zubin, J. Evoked potential correlates of information processing in psychiatric patients. Psychological Medicine, 3:487-494, 1973.

Lieberman, J. Evidence for a biological hypothesis of obsessive-compulsive disorder. Journal of Neuropsychobiology, 11:14-21, 1984.

Luxenberg, J.S.; Swedo, S.E.; Flament, M.F.; Friedland, R.P.; and Rapoport, S.I. Neuroanatomical abnormalities in obsessive-compulsive disorder detected with quantitative X-ray computed tomography. American Journal of Psychiatry, 145:1089-1093, 1988.

Mannuzza, S.; Fyer, A.J.; Klein, D.F.; and Endicott, J. Schedule for Affective Disorders and Schizophrenia-Lifetime Version, modified for the study of anxiety disorders: Rationale and conceptual development. Journal of Psychiatric Research, 20:317-325, 1986.

Miller, G.A. Information processing deficits in anhedonia and perceptual aberration: A psychophysiological analysis. Biological Psychiatry, 21:100-115, 1986.

Naatanen, R. Processing negativity evoked-potential reflection of selective attention. Psychological Bulletin, 92:605-640, 1982.

Naatanen, R. The role of attention in auditory information processing as revealed by event-related potentials and other brain measures of cognitive function. Behavioral and Brain Sciences, 13:201-288, 1990.

Naatanen, R., and Picton, T.W. The N1 wave of the human electric and magnetic response to sound: A review and an analysis of the component structure. Psychophysiology, 24:375$425,1987$.

Nordahl, T.E.; Benkelfat, C.; Semple, W.E.; Gross, R.; King, A.C.; and Cohen, R.R. Cerebral glucose metabolic rates in obsessive-compulsive disorder. Neuropsychopharmacology, 2:23-28, 1989.

Rapoport, J.; Elkins, R.; Langer, D.; Sceery, W.; Buchsbaum, M.; Gillin, J.C.; Murphy, D.L.; Zahn, T., Lake, R.; Ludlow, C.; and Mendelson, W. Childhood obsessive-compulsive disorder. American Journal of Psychiatry, 138:1545-1554, 1981.

Ritter, W.; Simson, R.; Vaughan, H.G., Jr.; and Fricdman, D. A brain event related to the making of a sensory discrimination. Science, 203:1358-1361, 1979.

Ross, C.A.; Siddiquei A.R.; and Matas, R. DSM-III: Problems in diagnosis of paranoia and obsessive-compulsive disorder. Canadian Journal of Psychiatry, 32:146-148, 1987.

Roth, W.T.; Duncan, C.C.; Pfefferbaum, A.; and Timsit-Berthier, M. Applications of cognitive ERPs in psychiatric patients. In: McCallum, W.C.; Zappoli, R.; and Denoth, F., eds. Cerebral Psychophysiology: Studies in Event-Related Potentials (EEG Suppl. 38). Amsterdam: Elsevier Science Publishers, 1986.

Ruchkin, D.S., and Glaser, E.M. Simple digital filters for examining CNV and P300 on a single-trial basis. In: Multidisciplinary Perspectives in Event-Related Potential Research. Chapel Hill, NC: Environmental Protection Agency (Publication \#EPA 60019-77-043), 1978. pp. 579-581.

Sartory, G., and Master, D. Contingent negative variation in obsessional-compulsive patients. Biological Psychology, 18:253-267, 1984.

Shagass, C.; Josiassen, R.C.; and Roemer, R.A. Psychiatric diagnostic differentiations by evoked potential measures: Results of a second series. Research Communications in Psychology, Psychiatry and Behavior, 13:43-75, 1988. 
Shagass, C.; Roemer, R.A.; Straumanis, J.J.; and Josiassen, R.C. Distinctive somatosensory evoked potential features in obsessive-compulsive disorder. Biological Psychiatry, 19:1507-1524, 1984a.

Shagass, C.; Roemer, R.A.; Straumanis, J.J.; and Josiassen, R.C. Evoked potentials in obsessive-compulsive disorder. Advances in Biological Psychiatry, 15:69-75, $1984 \mathrm{~b}$.

Towey, J.; Bruder, G.; Hollander, E.; Friedman, D.; Erhan, H.; Liebowitz, M.; and Sutton, S. Endogenous event-related potentials in obsessive-compulsive disorder. Biological Psychiatry, 28:92-98, 1990.

Towey, J.; Rist, F.; Hakerem, G.; Ruchkin, D.S.; and Sutton, S. N250 latency and decision time. Bulletin of Psychonomic Society, 15:365-368, 1980.

Tucker, D.M. Lateral brain function, emotion, and conceptualization. Psychological Bulletin, 99:19-46, 1981.

Tucker, D.M., and Williamson, P.A. Asymmetric neural control systems in human selfregulation. Psychological Review, 91:185-215, 1984.

Turner, S.M.; Beidel, D.C.; and Nathan, R.S. Biological factors in obsessive compulsive disorders. Psychological Bulletin, 17:430-450, 1985.

Verleger, R.; Gasser, T.; and Moecks, J. Correction of EOG artifacts in event-related potentials of the EEG: Aspects of reliability and validity. Psychophysiology, 19:472-480, 1982.

Wexler, B.E., and Goodman, W.K. Cerebral laterality, perception of emotion, and treatment response in obsessive-compulsive disorder. Biological Psychiatry, 29:900-908, 1991.

Williamson, P.D.; Allison, T.; Goff, W.R.; and Mattson, R.H. Evoked potential abnormalities in epilepsy: The E-wave. Electroencephalography and Clinical Neurophysiology, 42:729-730, 1977.

Zohar, J., and Insel, T.R. Obsessive-compulsive disorder: Psychobiological approaches to diagnosis, treatment, and pathophysiology. Biological Psychiatry, 22:667-687, 1987.

Zohar, J.; Insel, T.R.; Berman, K.F.; Foa, E.B.; Hill, J.L.; and Weinberger, D.R. Anxiety and cerebral blood flow during behavioral challenge: Dissociation of central from peripheral and subjective measures. Archives of General Psychiatry, 46:505-510, 1989. 